\title{
ГЛОБАЛЬНЫЕ РИСКИ МИРОВОЙ ЭКОНОМИКИ В УСЛОВИЯХ ПАНДЕМИИ КОРОНАВИРУСА
}

\author{
(c) 2021 Крум Димитров \\ аспирант \\ Санкт-Петербургский государственный экономический университет, Россия, Санкт-Петербург \\ E-mail: krumdimitrov1@gmail.com
}

В статье рассмотрено влияние пандемии коронавируса, которая бросила вызов обществу и экономике и усилила процессы трансформации в мировой экономике, такие как протекционизм, регионализация и цифровизация. Однако глобальные риски для здоровья, здравоохранения и общества имеют решающее значение для будущего существования экономики, и в то же время они являются довольно чувствительными проблемами для общества. В данной статье рассматривается дилемма между здоровьем/здравоохранением и экономикой, и обсуждается влияние глобальных социальных рисков на мировую экономику.

Ключевые слова: социальные глобальные риски, мировая экономика, пандемия.

Состояние международной экономики последние несколько десятилетий меняется в отношении ведущих процессов.

С начала 90-х годов 20 века ясно сформировались процессы глобализации, для развития которых ключевую роль сыграло развитие информационных технологий. Вопреки этому, с усилением миграционных процессов 20142015 г. протекционизм и развитие региональных взаимоотношений заметно усилились.

В данной статье рассмотрены и проанализированы влияние общественных и глобальных рисков на развитие мировой экономики. Объектом исследования являются процессы изменения мировой экономики в условиях пандемии коронавируса. Предмет исследования: методологические и теоретические основы и методы борьбы с экономическими последствиями пандемии.

Настоящая пандемия Коронавируса (novel coronavirus - 2019-nCoV), которая затронула почти все страны в мире, становится одной из серьезных проблем для будущего состояния и развития общества, и экономики. Однако это не единственная пандемия и эпидемия 21 века, вызванная вирусами.

Например, в 2003 г. была эпидемия SARS Коронавирус (SARS-CoV), которая, в основном распространилась в Азии. Первой пандемией этого тысячелетия была H1N1 (свинной грип) в 2009 году, которая затронула все континенты. В последующие годы в разных частях мира произошли вспышки других эпидемии, таких как Ко- ронавирус MERS (MERS-CoV) в 2012-2013 гг. на Ближнем Востоке и Эбола в 2014 г., Вирус Зика Западной Африке, в 2015 году, наконец, что не менее важно, следует отметить рецидив H5N1 («птичий грипп») с 1997 года.

Несмотря на наличие этих вирусных эпидемий и пандемий в последние годы, не было создано никаких предпосылок для такой блокады мировой экономики, которая наблюдается в настоящее время. Однако пандемия Коронавируса, вероятно, станет первой за столетие пандемией, которая внесет вклад в изменение экономических моделей и поведения в мире в целом, а также в отдельных регионах и странах. Кроме того, данные, представленные Всемирной организацией здравоохранения, лишь подтверждают наблюдения о том, что экономический рост и развитие до сих пор сопровождались стойкими эпидемиями и пандемиями и сосуществовали параллельно.

В любом случае быстрое и широкое распространение инфекционных заболеваний рассматривается как общественный глобальный риск [6]. Кроме того существуют другие возможные социальные риски, которые связаны с кризисами, вызванными нехваткой продовольствия и воды, плохим управлением урбанизацией, крупномасштабной миграцией и значительной социальной нестабильностью. Все общественные риски оказывают давление на системы здравоохранения отдельных стран и препятствуют нормальному функционированию мировой экономики. 
Что касается воздействия этой пандемии на экономику, то, несмотря на попытки сравнить ее с предыдущими кризисами 20 и 21 веков, оно совершенно иное. Как отмечает Г. Минасян: «Коронавирусный кризис в экономике несопоставим ни с кризисом 1930-х годов, ни с 1990-ми годами в нашей стране, ни с 2007-2008 годами по экономическим причинам. Его последствия будут экономическими, но восстановление экономики будет другим» [7].

Таким образом, решение дилеммы, отложенной на долгие годы, в настоящее время находится на первом месте. А именно, поддержание хорошей и доступной для большинства системы здравоохранения для заботы о здоровье людей или достижения экономического роста с участием части населения, которая здорова и не нуждается в медицинских услугах.

С одной стороны, система здравоохранения является результатом принятой модели в экономике [8]. Чаще всего системы здравоохранения оцениваются как инвестиции с низкой окупаемостью или вовсе без нее, т.е. они не так прибыльны, как, например, сектор информационных и коммуникационных технологий. Таким образом, финансирование сектора в большинстве стран возлагается на государственный бюджет, если, конечно, это не относится к частным медицинским учреждениям, некоторые из которых также используют бюджетные средства. Связанные со здоровьем секторы, такие как фармацевтика, химическая промышленность, производство расходных материалов, оборудования и других специализированных продуктов, также полностью зависят от финансирования, а не от здоровья человека. С другой стороны, это экономика отдельной страны и мировая экономика в целом. Предприятия работающие на основе производства и торговли, стремятся внести свой вклад в увеличение доходов от продажи товаров или услуг. Для отдельных стран важно поддерживать сбалансированный или профицитный бюджет, в то же время, формируя рост своей экономики, выраженный в ВВП. Таким образом, вместе с предприятиями и страны показали за последнее столетие, что, работая таким образом, они развиваются и способствуют увеличению роста мировой экономики. К этому следует добавить, что процессы глобализации с начала 1990-х ускорили изменения в отдельных секторах экономики.

Если предыдущие эпидемии и пандемии не уделяли достаточного внимания дилемме «крепкое здоровье и хорошее здравоохранение залог развитой экономики», то нынешняя пандемия Коронавируса сделала это.

Вызовы, стоящие перед мировой экономикой, были ясно выделены во время пандемии, но оказалось, что большинство из них, появились не сейчас, а назревали давно. Некоторые из них представляют собой отложенные меры, которые не пользуются популярностью или могут привести к серьезным последствиям для ряда секторов. На рис. 1 представлено краткое изложение существующих и возникающих проблем для решения.

Во-первых, это измерение и включение в материальное выражение ряда нематериальных параметров, таких как здоровье человека, благополучие, удовлетворение, знания, сочувствие и т.д. Они нематериальны, но чрезвычайно важны для существования людей, и, прежде всего, они способствуют проявлению их человеческой природы, которая в материальном мире неизмерима.

Конечно, в течение многих лет велись поиски способов денежной оценки этих параметров, и они были финансово отражены в нематериальных активах, но определение стоимости всегда вызывает споры. То что здоровый человек более продуктивен, чем больной является фактом, но измерить можно прежде всего стоимость системы здравоохранения. Как уже упоминалось, довольно часто системы здравоохранения недооцениваются и недофинансируются из-за нехватки средств, что делает эти нематериальные категории приоритетными для стран.

Даже после того, как нынешняя пандемия пройдет и эти нематериальные и трудно оцениваемые параметры будут снова недооценены, ожидается распространение инфекционных или других заболеваний аналогичного масштаба.

Во-вторых, к глобальным общественным рискам, помимо широкого распространения инфекционных заболеваний, относятся продовольственный и водный кризисы, проблемы урбанизации, т.е. когда много людей собирается в одном месте, появляется социальной нестабильность связанная с массовой миграцией. С другой стороны глобализация способствовала распределению производства и его концентрации в определенных частях мира, например Азия (Китай, Вьетнам, Индия и др.). Это создало специализацию и аутсорсинг деятельности из одной 


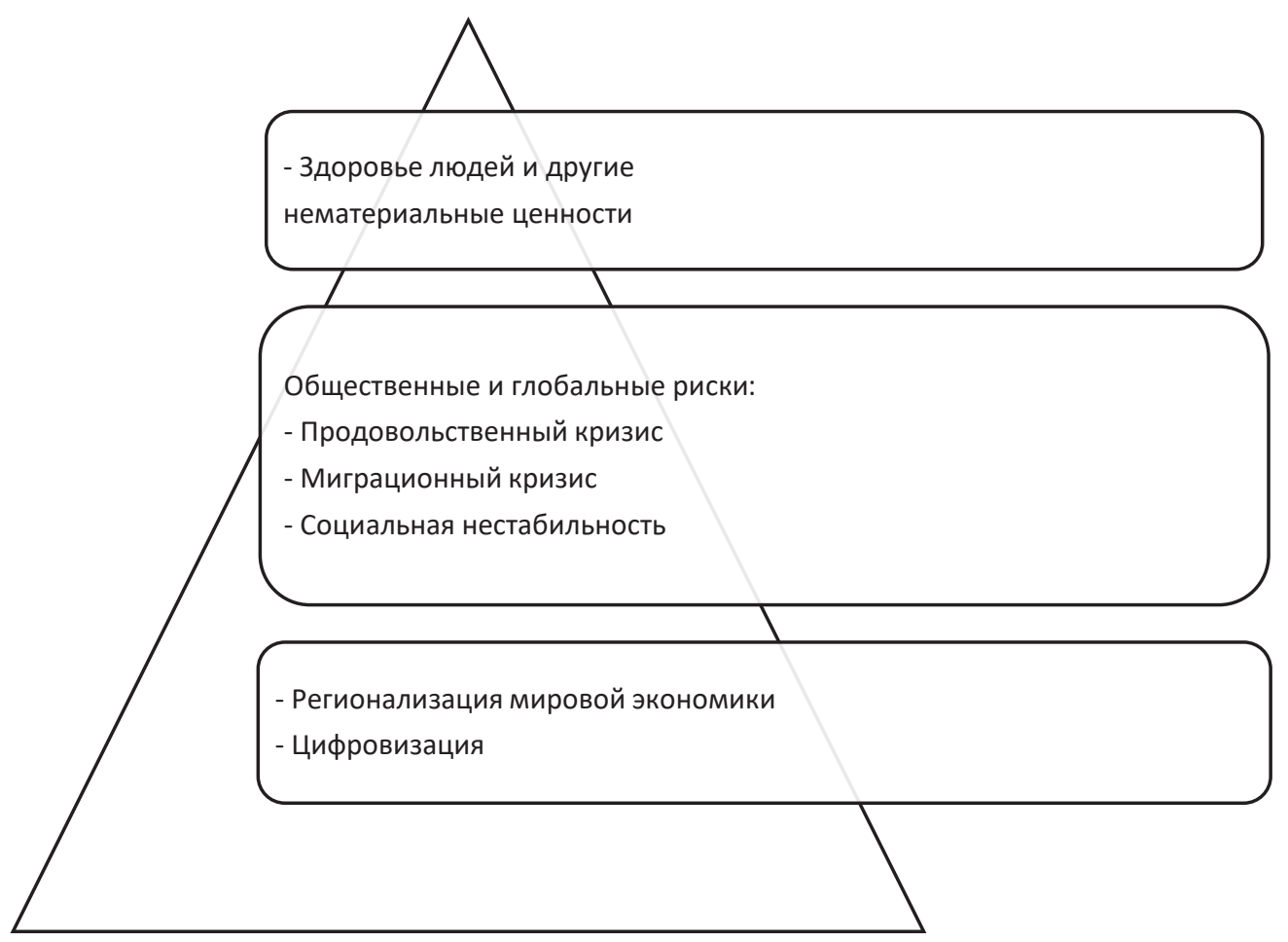

Рисунок 1. Основные проблемы мировой экономики во время пандемии (составлено авторами).

страны в другую, только ради увеличения доходов, но без учета культурной специфики местного населения и достаточности товаров первой необходимости.

Данная пандемия - это проверка функциональности мировой экономики перед лицом резко возрастающих общественных рисков. Оказалось, что первой реакцией было закрытие государств и забота о собственном населении, что и было сделано во всем мире. Только после этого мир перешел к сопереживанию и обмену в основном лекарствами, расходными материалами и оборудованием.

Пандемия фактически положила конец либерализации торговли и повлияла на существующую модель мировой экономики, основанную на глобализации и регулярных поставках товаров и услуг во всех частях мира. Оказалось, что инфекционное заболевание может внезапно положить конец экономике на несколько часов, учитывая, что в течение примерно двадцати лет были признаки неспособности справиться с вызовами в системе здравоохранения и распространением болезней. В случае крупномасштабного продовольственного и водного кризиса страны, которые не производят предметов первой необходимости и не имеют достаточного количества воды, сталкиваются с еще более се- рьезной проблемой, учитывая существующую модель специализации производства. Проблемы с едой и водой могут обостриться, если границы между странами снова закроют.

Что касается других глобальных социальных рисков, таких как миграция, социальная нестабильность и проблем, связанных с урбанизацией, то это особенно важные вопросы, которые необходимо решать, но только после окончания пандемии или, по крайней мере, после решения жизненно важных проблем для человечества.

В-третьих, мировой экономике придется отойти от принятого до сих пор подхода к полной либерализации и глобализации процессов, а также к специализации производства. Введение протекционистских мер это не новая политика для стран всего мира. Напротив, в 2018 и 2019 годах было введено 1000 новых мер, что примерно на 40\% больше, чем в предыдущие годы, при этом 23\% из них - в США и Китае [4]. Кроме того по данным МВФ, на 2020 год ожидается сокращение мировой экономики на 3\%, по крайней мере, по состоянию на 15 апреля 2020 г., и данные могут быть скорректированы, поскольку пандемия продолжится и третья волна может наступить до конца года. Помимо протекционизма, в последние годы можно говорить о регионализации, которая снова является формой 
сотрудничества в противовес глобализации [5]. Процессы регионализации и протекционизма особенно активно развивались после блокировки деятельности Всемирной торговой организации. И теперь пандемия снова выдвигает их на первый план как возможность решить проблему нехватки лекарств и предметов медицинского назначения.

Цифровизация мировой экономики - это процесс, который также развивается вместе с развитием информационных и коммуникационных технологий. При физическом удалении людей цифровые отрасли и виды деятельности не почувствуют наступления спада и ожидаемой рецессии в экономике. Напротив, ожидается, что они будут развиваться еще более быстрыми темпами, как и отрасли, которые можно быстро реформировать в сторону цифровизации. Связь между этими тремя элементами - здоровьем, общественными глобальными рисками и глобальной экономикой - следует искать в общих точках соприкосновения и возможностях преодоления последствий пандемии Коронавируса.

Возможности для мировой экономики в условиях текущей пандемии, а также в случае возможной вспышки других заболеваний аналогичного масштаба следующие:

Учитывая чрезвычайные обстоятельства и ожидания продолжения инфекционных заболеваний, отдельные страны должны подготовить собственное производство, так называемых, товаров первой необходимости или предметов снабжения (продукты питания, вода, лекарства и медицинские принадлежности). Только тогда они смогут ответить на регионализацию и сотрудничество с соседними странами;

Преодоление пандемии, помимо отдельных стран, должно быть пересмотрено как общий подход к стратегическому решению на региональном или глобальном уровне, по крайней мере, до открытия эффективных лекарств или методов лечения, отличных от установления социальной дистанции. Если не предпринять согласованных действий и при наличии отдельных очагов болезни, могут возникнуть дальнейшие волны распространения, независимо от индивидуальных мер.

Реструктуризация существующих секторов, а также секторов, которые, как ожидается, переформатируются или исчезнут, является ключом к подготовке экономики к пост пандемическому периоду или в период пандемии, если он продолжится до создания вакцин. Судя по всему, это рецессия, в которой оцифрованные виды деятельности и отрасли пострадают меньше тех, которые связаны с прямым контактом между людьми [6]. Это подразумевает не только рост безработицы, но и изменение квалификации рабочей силы, особенно если определенные секторы перестанут быть актуальными после окончания пандемии.

Учитывая тот факт, что эпидемии продолжаются годами, системы здравоохранения также подлежат реструктуризации и переосмыслению. Более того, есть несколько факторов, которые еще больше затрудняют преодоление подобных кризисных ситуаций:

- отсутствие достаточно подготовленных специалистов здравоохранения, что требует времени;

- устойчивость вирусов и микроорганизмов к лекарствам, что усложняет процесс исследования и последующего массового производства;

- инновационные лекарства намного дороже и мало доступны широкой публике и т.д.

Другие социальные глобальные риски также не следует недооценивать, особенно в связи с их взаимосвязанностью. В краткосрочной перспективе это относится в основном к возможным продовольственным и водным кризисам, которые продиктованы неравномерным распределением ресурсов в мире и особенно к запасам питьевой воды.

Как показывают данные за последние двадцать лет, человечество по-прежнему уязвимо для вирусов и инфекционных заболеваний как часть глобальных рисков общества. Но до сих пор у нас не было четкого представления о возможных последствиях быстрого роста и возможного масштаба, несмотря на частичные предупреждения от местных эпидемий и первой в 21 веке пандемии.

Пандемия Коронавируса, безусловно, изменит способ функционирования мировой экономики, которая, скорее всего, не вернется к прежним методам функционирования. Даже после открытия вакцины или лекарства для лечения вируса осторожность в отношениях с людьми будет сохраняться из-за вероятности новой эпидемии. Таким образом, секторы экономики, которые могут быстро оцифроваться, понесут меньше потерь и, как ожидается, будут быстрее адаптироваться.

Тем не менее, остаются вопросы поставлен- 
ные в начале этой статьи о взаимосвязи между:

1. Здоровьем и текущим медицинским обслуживанием.

2. Необходимо продолжать искать решения проблем с системами здравоохранения. Только при наличии правильно работающих медицин- ских учреждений и здорового населения можно ожидать экономического роста и развития. Потому что инновации по-прежнему изобретаются людьми, а без здоровых людей не может быть инноваций и будущего развития экономики.

\section{Библиографический список}

1. Подберезкин А. И., Александров М. В. Стратегическое прогнозирование международных отношений: коллективная монография: Изд-во МГИМО-Университет, 2016.-743c.

2. Бондаренко В. М., Румянцеева С. Ю., Дементьев В.Е., Клинов В. Г, Гринин А. Л., Малков С. Ю., Исаев Л. М., Шишкина А.P., Кризисы и прогнозы в свете теории длинных волн: Изд-во ООО «Издательство «Учитель», 2016368c.

3. Chletsos M., Saiti A., Strategic Management and Economics in Health Care. Springer Nature, 2020-134p.

4. Bradshaw A., Hietanen J., The Dictionary of Coronavirus Culture. Watkins Media Limited, 2020-150p.

5. Skirbekk G., Epistemic Challenges in a Modern World: From «fake news» and «post truth» to underlying epistemic challenges in science-based risk-societies. LIT Verlag Münster, 2019-88p.

6. Dr. Prita D. Mallya, Dr.Rodney D’Silva., Impact Of Covid - 19 Crisis On The Global Economy And Other Sectors Worldwide. Idea Publishing, 2020-352p.

7. Официальный сайт «Мировой Организации Здравоохранения» «WHO» [Электронный pecypc]. URL: https:// www.who.int/director-general/speeches/detail/who-director-general-s-opening-remarks-at-the-media-briefingon-covid-19--11-march-2020 (дата обращения: 01.11.2020).

8. Официальный сайт научного журнала «Экономическая жизнь» (перевод с болгарского языка) [Электронный ресурс]. URL: https:/ikj.bg/glasove-mneniya/koronavirus-ikonomika-merki-inflacia/ (дата обращения: 30.10.2020).

9. Международный Валютный Фонд. Перспективы развития мировой экономики. Замедление роста, неустойчивый подъем.: Изд-во АПР 2019.

10. Официальный сайт «Международного Валютного Фонда» [Электронный ресурс]. URL: https://blogs.imf. org/2020/04/14/the-great-lockdown-worst-economic-downturn-since-the-great-depression/ (дата обращения: 29.10.2020).

11. United Nations: World Economic Situation and Prospects 2020, United Nations, 16 Jauary, 2020._-236p. 